\title{
First Experience of Intra-Operative Radiation Therapy (IORT) during Kyphoplasty in Patients Diagnosed with Spinal Metastasis in Iran
}

\author{
Seddighi AS ${ }^{1}$, Nikouei $A^{2}$, Seddighi $A^{1 *}$, Akbari \\ $\mathrm{ME}^{3}$, Arjmand $\mathrm{Y}^{2}$, Ommi $\mathrm{D}^{4}$, Zali $\mathrm{A}^{5}$ and Hosseini \\ $\mathbf{M}^{2}$
}

${ }^{1}$ Shohada Tajrish Comprehensive Neurosurgical Center of Excellence, Functional Neurosurgery Research Center of Shohad Tajrish Hospital, Shahid Beheshti University of

Medical Sciences, Tehran, Iran

${ }^{2}$ GP Member of Shohada Tajrish Comprehensive

Neurosurgical Center of Excellence, Functional

Neurosurgery Research Center of Shohad Tajrish

Hospital, Shahid Beheshti University of Medical Sciences,

Tehran, Iran

${ }^{3}$ Cancer Research Center, Shohada Tajrish Hospital,

Shahid Beheshti University of Medical Sciences, Tehran,

Iran

${ }^{4}$ Shohada Tajrish Comprehensive Neurosurgical Center of Excellence, Functional Neurosurgery Research Center of Shohad Tajrish Hospital, Shahid Beheshti University of Medical Sciences, Tehran, Iran

${ }^{5}$ Shohada Tajrish Comprehensive Neurosurgical Center of Excellence, Functional Neurosurgery Research Center of Shohad Tajrish Hospital, Shahid Beheshti University of Medical Sciences, Tehran, Iran

*Corresponding author: Afsoun Seddighi, Associate Prof of Neurosurgery. Shohada Tajrish Comprehensive Neurosurgical Center of Excellence, Functional

Neurosurgery Research Center of Shohad Tajrish

Hospital, Shahid Beheshti University of Medical Sciences, Tehran, Iran

Received: April 22, 2021; Accepted: May 13, 2021; Published: May 20, 2021

\begin{abstract}
Object: Based on previous studies, 30 to $40 \%$ of cancer patients are diagnosed with bone metastasis. Median Overall Survival (OS) of patients who are diagnosed with spinal metastasis (vertebral structures) is about 7 to 9 months which with recent progresses in oncologic and radiotherapy treatment modalities, their prognosis is slightly developed. In this study, authors plan to evaluate the effects of Intra-operative Radiation Therapy (IORT) in patients who are candidate for Kyphoplasty procedure.
\end{abstract}

Methods: In this study, we have included patients who are diagnosed with spinal metastasis with radiological and histopathological confirmation. From July 2017 to December 2018, we have included 9 patients who fulfilled our predefined inclusion and exclusion criteria into our case-series study performed on Shohada Tajrish Hospital. Patients underwent radiotherapy during Kyphoplasty by our IORT device INTRABEAM (Carl Zeiss AG, Germany) as "Kypho-IORT' procedure. We have evaluated these patients in post-operative period, as well as on 2 weeks, 1 month, 2 months and 6 months on post-operative period as our follow-up plan.

Results: In this study, 9 patients (5 males and 4 females) with mean age of 68 years with spinal metastasis from breast (4 cases), prostate (2 cases), lung ( 2 cases) and gastrointestinal tract (1 case), underwent Kypho-IORT for 15 vertebrae levels with individualized radiation dose and interval. In postoperative follow-up period, patients exhibit pain relief (in 78\%) assessed by Visual Assessment Score (VAS) and improvement in their Quality of Life (QoL). No major complications including new neurological deficit, major cement leak and embolic disorders were encountered during the study; however, minor cement leak encountered in 4 cases, and 2 patients have expired during follow up period; however, other patients are still alive and under follow-up with mean OS of 10 months.

Conclusion: This study is the first experience of evaluation of IORT effects during Kyphoplasty in Iran, in patients diagnosed with spinal metastasis with poor prognosis, to improve their quality of life, local control rate and their OS. This study could be considered as one of the pioneers in continuing the evaluation of Kypho-IORT as a novel technique in these group of patients.

Keywords: Intra-operative radiation therapy; Kyphoplasty; Overall survival; Kypho-IORT

\section{Introduction}

In general, 30 to $40 \%$ of patients diagnosed with cancer, somehow develop bone metastasis in later stages [1]. Among these metastasis, more than half of them occur in spine, mostly in thoracic spine from T4 to T7 in $70 \%$ of the cases, followed by lumbar and cervical spine with 20 and $10 \%$ respectively [2]. Common complications of spinal metastasis include central axis pain, pathologic fractures and neurologic disorders secondary to spinal cord compression. Although the overall survival rate of these patients is reported to be from 7 to 9 months, application of optimal oncologic therapeutic procedures has improved the mentioned value in recent years [3]. Therefore, utilization of advanced therapeutic regiments for patients suffered from bony metastasis is essential to enhance their quality of life. In recent years, Oncologists have suggested employment of Radiotherapy (RT) adjacent to chemotherapy regiments for better bony metastasis control [4]. At first, External Beam Radiotherapy (EBRT) was one the most effective procedures in management of patients with spinal metastasis, ranging from 8 to 40 Gray (Gy), in 1 to 20 units, respectively [5]. Also, EBRT was reported to be effective in pain alleviation just few days following its application in enrolled patients [6].

However, due to medium 6-month period required for repeated calcium deposition in spinal column bones, patients were always faced fracture risk in mentioned interval; thus, surgical interventions 
such as vertebral augmentation is justified to preserve an adequate stability. Since justification of post-operative RT for prevention of early regrowth of malignant tissues, application of RT in $2^{\text {nd }}$ to $4^{\text {th }}$ postoperative period is suggested [7]. Existing evidence suggest promising reports of spine Stereotactic Body Radiotherapy (SBRT) with splitdose from 1 to 5 units to reduce treatment period, remarkable local control and pain control equivalent or even superior to EBRT [8].

Another technology for cancer control in the scope of RT is intraoperative radiotherapy (IORT) which consists of focused radiation to tumor bed intra-operatively. IORT is capable of delivering high amounts of radiation dosages to the tumor's bed in a precise manner, sparing healthy tissue from excessive radiation [9]. Commonly, IORT is used coupled with other therapeutic modalities, such as various surgical techniques to achieve maximum tumor resection, EBRT and chemotherapy as a part of multidisciplinary approach [10]. Until now, no definite method is proven to increase their life expectancy and all of the studies and trials, exhibited variable results. Experts aim to control pain and maintain patient's functionality in different aspects. Between among all suggested therapeutic approaches, RT remains the principal management approach in these patients. Authors aim to discuss their first experience of spinal IORT in Iran.

\section{Materials and Methods}

This study is a clinical trial with aim to evaluate the effect of addition of IORT technique to kyphoplasty procedure in patients diagnosed with spinal metastasis. Demographic data of patients collected and documented by observation and interview, as well as their underlying diseases. Also, intervention techniques through direct observation of operation field and radiation were documented. Patients with age range of 18 to 80 years with spinal metastasis which was confirmed by radiological and histopathological evaluations who were kyphoplasty candidates were included in the study. Our exclusion criteria were previous history of IORT to the same involved location, presence of primary bone tumors or neural tissue tumors of spine (extradural, intra-dural, extra-medullary and intra-medullary), presence of any local soft tissue infection or systemic infection leading to patient deterioration, presence of underlying anatomic disorder of spinal column which results in inability to maintain IORT applicators in desired place, previous history of spinal column fractures or osteoporosis in spinal column (defined as T-score less than -2.5), hazardous anesthesia induction and patient's failure to give consent based on provisions of World Medical Association Declaration of Helsinki in 1964. After effective act of our defined inclusion and exclusion criteria, 9 patients who suffered from underlying cancer with spinal metastasis and candidate for kyphoplasty surgical procedure were enrolled to neurosurgical department of Shohada Tajrish hospital from July 2017 to December 2019. At admission, pain assessment was performed using Visual Assessment Score (VAS). Also, performance ability of these patients were evaluated and documented by Karnofsky Performance Score (KPS) and Oswestry Disability Index (ODI). Intervention consist of RT with INTRABEAM (Carl Zeiss AG, Germany) with needle applicator, with consult of radio-oncologists during kyphoplasty operation with both closed and open methods. Alongside mentioned factors, authors introduced complementary variables including sex, bone mineral density, patient's chief complaint, tumor to surface distance, histopathological examination, metastasis number, vertebral body involvement, vertebral instability, lesion type (lytic or blastic), duration of underlying cancer, extra-vertebral involved viscera, duration of metastasis spread to vertebrae, kyphoplasty type (open or closed), anesthesia type, beam illumination type (one sided or two sided), radiation duration, total radiation dosage, American Society of Anesthesiologists (ASA) score, post-operative complications, post-intervention cancer progress, post-intervention vertebral deformity, focal neurologic deficit at $2^{\text {nd }}$ post-operative month, depth dose measurement, dosage homogeneity and applicator distance to tumor's core. Patients were scheduled to be evaluated at $2^{\text {nd }}$ postoperative week, along with $1^{\text {st }}, 2^{\text {nd }}$ and $6^{\text {th }}$ post-operative month for neurological assessment and investigation of possible complications and radiological surveys.

\section{Results}

Nine patients, including 5 males and 4 females, with mean age of 68 years with confirmed diagnosis of spinal metastasis entered in study. From these patients, 4 cases were found that their metastasis have spread from breast cancer, followed by 2 from prostate cancer, 2 from lung cancer and one patient from his gastrointestinal malignancy. Pre-operative details of our patients based on the included variables are summarized in Table 1.

Table 1: Patient's demographics initial characteristics.

\begin{tabular}{|c|c|c|c|c|c|c|c|c|}
\hline $\begin{array}{l}\text { Patient } \\
\text { Number }\end{array}$ & $\begin{array}{c}\text { Patient's } \\
\text { Demographic } \\
\text { (Age (years) - } \\
\text { Sex) }\end{array}$ & $\begin{array}{c}\text { Underlying Cancer } \\
\text { Duration }\end{array}$ & $\begin{array}{c}\text { Underlying Cancer } \\
\text { Type }\end{array}$ & $\begin{array}{l}\text { Spinal Metastasis } \\
\text { Duration }\end{array}$ & C.C. & $\begin{array}{l}\text { Pre-op } \\
\text { VAS }\end{array}$ & $\begin{array}{l}\text { Pre-op } \\
\text { KPS }\end{array}$ & $\begin{array}{l}\text { Pre-op ODI } \\
(\%)\end{array}$ \\
\hline 1 & $45-F$ & 12 months & Breast & 5 months & LBP & 9 & 40 & 88 \\
\hline 2 & $54-M$ & 14 months & Prostate & 3.5 months & LBP & 9 & 50 & 86 \\
\hline 3 & $42-F$ & 9 months & Breast & 4 months & $\begin{array}{l}\text { LBP+lower limb } \\
\text { paresis }\end{array}$ & 10 & 30 & 90 \\
\hline 4 & $52-F$ & 8.5 months & Breast & 3 months & $\begin{array}{l}\text { Lower limb } \\
\text { paresthesia }\end{array}$ & 6 & 50 & 78 \\
\hline 5 & $58-M$ & 5 months & Lung & 3 months & LBP & 8 & 40 & 82 \\
\hline 6 & $62-M$ & 9 months & Lung & 4 months & LBP & 9 & 40 & 86 \\
\hline 7 & $49-M$ & 13 months & Prostate & 4.5 months & $\begin{array}{c}\text { Urinary } \\
\text { incontinency }\end{array}$ & 6 & 40 & 88 \\
\hline 8 & $60-F$ & 15 months & Breast & 6 months & LBP & 8 & 50 & 84 \\
\hline 9 & $65-M$ & 12 months & Colon & 3 months & LBP & 9 & 30 & 92 \\
\hline
\end{tabular}

Abbreviations: Pre-op: Pre-operative; C.C.: Chief Complain; VAS: Visual Assessment Score; KPS: Karnofsky Performance Score; ODI: Oswestry Disability Index; LBP: Low Back Pain. 
Table 2: Pre-operative details of affected spine levels.

\begin{tabular}{|c|c|c|c|c|c|c|}
\hline Patient Number & Lesion Type & Lesion Location & Vertebral Involvement Type & Associated Involvements & SINS & Extra Spinal Spread \\
\hline 1 & Lytic & Pedicle of L1 and L2 & $\begin{array}{l}\text { Intra-compartmental } \\
\text { Type II: L1 } \\
\text { Type I: L2 }\end{array}$ & L2-L3 instability & 13 & N/A \\
\hline 2 & Blastic & Body of L4 & $\begin{array}{c}\text { Intra-compartmental } \\
\text { Type I }\end{array}$ & Pathologic $\mathrm{fx}$ in $\mathrm{L} 4$ & 15 & Brain \\
\hline 3 & Lytic & Pedicle of L3 & $\begin{array}{c}\text { Intra-compartmental } \\
\text { Type III }\end{array}$ & Pathologic fx in L3 & 12 & Brain \\
\hline 4 & Lytic/Blastic & Pedicle of L4 & $\begin{array}{c}\text { Intra-compartmental } \\
\text { Type II }\end{array}$ & N/A & 10 & N/A \\
\hline 5 & Blastic & Body of L4 & $\begin{array}{c}\text { Intra-compartmental } \\
\text { Type I }\end{array}$ & Instability of L4-L5 & 15 & Extra-peritoneal LNs \\
\hline 6 & Lytic & Pedicle of L2 and L3 & $\begin{array}{l}\text { Intra-compartmental } \\
\text { Type II: L2 and L3 }\end{array}$ & Instability of L2-L3 & 14 & Brain and extra-peritoneal LNs \\
\hline 7 & Blastic & Body of L4 & $\begin{array}{c}\text { Intra-compartmental } \\
\text { Type I }\end{array}$ & Pathologic $\mathrm{fx}$ in $\mathrm{L} 4$ & 16 & N/A \\
\hline 8 & Lytic/Blastic & Pedicle of L2 & $\begin{array}{c}\text { Intra-compartmental } \\
\text { Type III }\end{array}$ & $\mathrm{N} / \mathrm{A}$ & 12 & Brain and liver \\
\hline 9 & Lytic & Body and pedicle of $L 4$ & $\begin{array}{c}\text { Intra-compartmental } \\
\text { Type I }\end{array}$ & Instability of L4-L5 & 14 & N/A \\
\hline
\end{tabular}

Abbreviations: SINS: Spine Instability Neoplastic Score; fx: Fracture; LN: Lymph Node; N/A: Not Applicable.

Table 3: Intervention's specifics on individual basis.

\begin{tabular}{|c|c|c|c|c|c|c|c|}
\hline $\begin{array}{l}\text { Patient } \\
\text { Number }\end{array}$ & ASA & $\begin{array}{l}\text { Kyphoplasty } \\
\text { Type }\end{array}$ & $\begin{array}{c}\text { Surface to Needle Applicator } \\
\text { Distance }\end{array}$ & $\begin{array}{l}\text { Radiation } \\
\text { Dosage }\end{array}$ & $\begin{array}{l}\text { Radiation } \\
\text { Duration }\end{array}$ & Radiation Type & Additional Therapies \\
\hline 1 & 4 & Closed & $10 \mathrm{~mm}$ & 6 Gy & 4 minutes & One sided & Adjuvant RT \\
\hline 2 & 4 & Closed & $10 \mathrm{~mm}$ & 8 Gy & 3 minutes & One sided & $N / A$ \\
\hline 3 & 3 & Open & $10 \mathrm{~mm}$ & 8 Gy & 3 minutes & One sided & $\begin{array}{l}\text { Neo-adjuvant } \\
\text { RT+Chemo }\end{array}$ \\
\hline 4 & 3 & Closed & $10 \mathrm{~mm}$ & 6 Gy & 4 minutes & One sided & N/A \\
\hline 5 & 4 & Open & $10 \mathrm{~mm}$ & 8 Gy & 3 minutes & One sided & Neo-adjuvant Chemo \\
\hline 6 & 4 & Open & $10 \mathrm{~mm}$ & 8 Gy & 3 minutes & Two sided & Adjuvant RT \\
\hline 7 & 4 & Closed & $10 \mathrm{~mm}$ & 8 Gy & 3 minutes & One sided & N/A \\
\hline 8 & 4 & Closed & $10 \mathrm{~mm}$ & $6 \mathrm{~Gy}$ & 4 minutes & One sided & Adjuvant RT \\
\hline 9 & 3 & Closed & $10 \mathrm{~mm}$ & 6 Gy & 4 minutes & One sided & Neo-adjuvant Chemo \\
\hline
\end{tabular}

Abbreviations: ASA: American Society of Anesthesiologists; mm: millimeters; Gy: Gray; Chemo: Chemotherapy; N/A: Not Applicable.

Table 4: Post-operative follow-up period performance assessment.

\begin{tabular}{|c|c|c|c|c|c|c|c|c|c|c|c|c|c|c|c|}
\hline \multirow{2}{*}{ Patient Number } & \multicolumn{5}{|c|}{ VAS } & \multicolumn{5}{|c|}{ KPS } & \multicolumn{5}{|c|}{ ODI (\%) } \\
\hline & Pre-op & $2^{\text {nd }} W$ & $1^{\text {st }} M$ & $2^{\text {nd }} M$ & $6^{\text {th }} M$ & Pre-op & $2^{\text {nd }} W$ & $1^{\text {st }} M$ & $2^{\text {nd }} M$ & $6^{\text {th }} M$ & Pre-op & $2^{\text {nd }} W$ & $1^{\text {st }} M$ & $2^{\text {nd }} M$ & $6^{\text {th }} M$ \\
\hline 1 & 9 & 1 & 5 & 3 & 0 & 40 & 50 & 50 & 40 & 40 & 88 & 74 & 76 & 80 & 78 \\
\hline 2 & 9 & 0 & 3 & 3 & 1 & 50 & 50 & 60 & 60 & 50 & 86 & 80 & 72 & 74 & 78 \\
\hline 3 & 10 & 1 & 4 & 3 & 2 & 30 & 50 & 50 & 60 & 50 & 90 & 80 & 78 & 76 & 70 \\
\hline 4 & 6 & 0 & 2 & 2 & 2 & 50 & 60 & 50 & 50 & 50 & 78 & 68 & 70 & 72 & 70 \\
\hline 5 & 8 & 2 & 3 & 3 & 1 & 40 & 60 & 60 & 50 & 60 & 82 & 74 & 74 & 80 & 76 \\
\hline 6 & 9 & 2 & 2 & $\mathrm{~N} / \mathrm{A}$ & $\mathrm{N} / \mathrm{A}$ & 40 & 50 & 50 & N/A & N/A & 86 & 80 & 82 & N/A & N/A \\
\hline 7 & 6 & 0 & 0 & 1 & 2 & 40 & 60 & 60 & 50 & 50 & 88 & 76 & 74 & 74 & 80 \\
\hline 8 & 8 & 1 & 3 & 3 & $\mathrm{~N} / \mathrm{A}$ & 50 & 50 & 60 & 50 & N/A & 84 & 72 & 78 & 76 & $\mathrm{~N} / \mathrm{A}$ \\
\hline 9 & 9 & 4 & 2 & 2 & 3 & 30 & 50 & 50 & 60 & 50 & 92 & 78 & 82 & 80 & 82 \\
\hline
\end{tabular}

Abbreviations: VAS: Visual Assessment Score; KPS: Karnofsky Performance Score; ODI: Oswestry Disability Index; Pre-op: Pre-operative; N/A: Not Applicable (due to expire of the patient).

They underwent Kypho-IORT for 15 vertebral levels, with discrete and individualized radiation dosage and interval which its details are demonstrated in Table 2 and Table 3.

In post-operative period, patients underwent their pre-scheduled follow-up program at $2^{\text {nd }}$ week and $1^{\text {st }}, 2^{\text {nd }}$ and $6^{\text {th }}$ month. Quality of life assessment performed using analysis of KPS and ODI, which revealed improvements in overall evaluation in our enrolled patients. Also, patients exhibited significant pain reduction through VAS report, by $78 \%$ in post-operative period follow-up examination. Nonetheless, no major complications, such as new neurological deficit or worsening of previous deficit, major cement leak, surgical site infection, embolic events and delayed complicated wound healing observed in our follow-up period. Albeit, minor complications including negligible cement leak reported in four patients. Also, cases expired secondary to their vast metastasis spread in follow-up period in their $2^{\text {nd }}$ and $5^{\text {th }}$ 
month respectively. However, other 7 patients are still alive to this date and under follow-up with mean overall survival of 10 months. Detailed data of follow-up period are given in Table 4.

\section{Discussion}

Spinal column is the third common site in distribution of malignant cells in metastasis process which follows lungs and liver. Bony metastasis of spine affects male more than females, mostly in their fourth to mid-sixth decade. Fortunately, only $10 \%$ of these patients manifest symptoms and among them, 94 to $98 \%$ present with bony or epidural involvement. Usually, cancerous cells spread through spine via arterial routes from primary tumor. Also, dissemination of these cells following Valsalva maneuver through Batson plexus is documented, along with direct invasion of cancerous cells through intervertebral foramens. Nearly half of the patients diagnosed with spinal metastasis suffer from multiple vertebrae involvement and 10 to $38 \%$ endured multiple non-conjunction level involvements [11]. Most of these lesions are found in anterior vertebral body (about $60 \%$ ), followed by vertebral pedicle and lamina (about $30 \%$ ); however, metastatic lesions were reported in both anterior and posterior vertebral bodies. Invaded cancerous cells to spinal column are mostly originates from followings: lungs (31\%), breasts (9\%), prostate (8\%), lymphoma (6\%), melanoma (4\%), unknown sources (2\%), kidneys (1\%) and other malignancies including multiple myeloma (3\%). In cases of no intervention, poor prognosis expects patients with spinal metastasis [12].

Radiotherapy remains the mainstay of the treatment of spinal metastasis. Most of the lympho-reticular tumors and prostate carcinomas are resistant to RT, while lung and breast tumors demonstrate sensitivity [13]. Also, gastrointestinal and renal malignancies, as well as melanomas are relatively resistant to RT. However, based on conducted studies, nearly $80 \%$ of the patients who exhibit pain before initiation of their treatment, demonstrated symptom improvement and about $48 \%$ of patients suffered from movement and sphincter disorders, responded to RT [14]. Commonly, RT regimen is suggested at 30 Gy divided to 10 doses. Although, radiation amount is somehow experimental and depends on the therapeutic relative, power of the performance of splitted dose and its biological effect on tissue, and durability of spine and vessels and neural roots. Allowed dose for each tissue is a parameter which relies on radiation volume performance, transferred dose in each fraction and acceptable measure of radiation risk [15]. Later phrase depends on proliferative potency of tissue cells. Therefore, skin and bone marrow tissues are affected more promptly than brain and spine to RT. Besides, subacute effect secondary to demyelination occurs following oligodendrocytes and vascular trees. For instance, the amount of divided dose for spinal necrosis is defined at 1.8 to 2 centigray daily [16].

According to previous studies, the biological effectiveness divided dose consists of multiple factors, such as restoration of severe non-lethal injuries, repeated oxygenation of hypoxic cells and rearrangement of multiplying cells in cell cycle and population redistribution [17]. Progresses in imaging programs (such as Computed Tomography (CT) and Magnetic Resonance Imaging (MRI)) have increased the accuracy of the data regarding tumor location and nearby healthy tissues. Based on conventional methods,
RT consist of enrollment and consideration of 2 upper and lower vertebral bodies in relative to the lesion, which its logic is built on the idea of the possibility of recurrence in adjacent vertebrae [18]. Mentioned developments in targeted RT based on image-guidance, resulted in emergence of stereotactic radiosurgery formed on Intensity-Modulated Radiation Therapy (IMRT) which is capable of irradiating heterogen beams with diverse intensities and in any desired amount. Previous system leads to fortified focus power and decreased radiation to adjacent healthy tissues. IMRT optimizes 3D programming with 12 to 15 millimeters accuracy [19]. Moreover, application of stereotactic radiosurgery and IMRT gained popularity in treatment planning for spinal metastasis. In recent two decades, technologies such as Robotic Linear Accelerator (LINAC) with free movement capability in 3D space (CyberKnife: Accuray, Sunnyvale, CA) has been introduced. This method brings the possibility of increasing same path beams. Also, live target persuasion system with 1 millimeter accuracy has strengthened its precision [20]. A clinical trial conducted by Radiotherapy and Oncology Group (RTOG 97-14) by CyberKnife on patients with spinal metastasis, revealed symptom improvement in 50 to $80 \%$ of the cases in 3 months' follow-up. Also, this study reports movement ability in $78 \%$ of the cases followed by some movements in 16 and complete paralysis in $4 \%$, which gained some functionality after the procedure [21].

On the other hand, effectiveness of IORT has been reported in multiple cancer control realms, including recurrent or advanced focal intestinal cancer, retroperitoneal sarcomas, pancreatic cancers, early stages of breast cancer and particular types of male and female urologic malignancies [22]. As yet, various methods of radiation with IORT is suggested, such as electron IORT (e-IORT), $\mathrm{x}$-ray IORT (kV IORT) and high dose brachytherapy IORT (HDRIORT). IORT technology first began with introduction of e-IORT in early 1960. In this method, variable electron energies are utilized to reach appropriate distribution of radiation depth to maintain radiation control and uniform focal distribution [23]. Nonetheless, application of mentioned technology is limited to transfer of patients from operation rooms to RT departments with observation of safety principles and maintenance of sterility. To solve previous issue, operation rooms turned to single units' compatible with RT technologies in some states of United States and European countries following high expenditures [24].

With appearance of small linear radiating machines with mobile lead shield in 1990s, IORT faced a renovation and utilization of this technology became pragmatic in most of medical centers worldwide. IORT prevailed $\mathrm{kV}$-IORT and HDR-IORT in its improved penetration depth and relative uniform radiation. Electron IORTs equipped with disparate applicators in shape and size for medical usage in different part of human's body with radiation procedure in a matter of minutes [25]. Albeit, due to physical rigidity, application of these applicators was challenging in hard to reach anatomical locations, such as pelvic fossa and other narrow cavities. Since mentioned applicators were competent for radiation a diameter of maximum $15 \mathrm{~cm}$, RT to larger areas required repeated efforts [26]. Application of D-type (Squircle) and rectangle shape applicators made broad fields radiation feasible. With respect to plummet slope of radiation, HDR-IORT have a dosimetric dominance in relative to other technologies and could decrease radiation to adjacent sensitive 
surrounding tissues, meanwhile preserves strong focused radiation to tumor bed [27]. Despite more simple relocation of HDR compared to other radiation technologies, incorporated operation room should comply with safety protocol for enhanced radiation protection. For utilization of HDR-IORT in many centers, Harrison-Anderson-Mick (HAM) or Superflab applicators in 0.5 to $1 \mathrm{~cm}$ depth is used [28] Cited applicators are flexible and can be used in uneven surfaces, with diverse sizes for different therapeutic purposes. Alongside quoted advantages of HDR-IORT, low penetration depth and prolonged radiation interval lowers its efficacy compared to e-IORT. With increasing utilization of e-IORT in 1980, x-ray orthovoltage was used to decrease radiation protection cost in IORT. Nevertheless, due to decreased appropriate uniformity, high bony radiation dose and prolonged procedure interval, the technology lost its popularity [29]. However, in recent years, mobile IORT with low voltage (about 20 to $50 \mathrm{kV}$ ) such as INTRABEAM (Carl Zeiss AG, Germany) and electronic brachytherapy system Axxent (Fremont, California Xoft Inc.) gained significant popularity in IORT field [30]. These systems harbor gradient radiation slope and do not require special protection equipment and its applicators are sphere shape with different sizes and seldom infiltration depth $(0.5$ to $1 \mathrm{~cm})$, thus making these devices a proper tool for targets with sphere shapes, or in spherical cavities [31].

Despite the controversial reports of competence of IORT in patients with spinal metastasis and different viewpoint, we evaluated the efficacy of IORT during Kyphoplasty for the first time in the country, with promising report of decreased pain score on VAS and improved quality of life of our enrolled patients, based on KPS and ODI, while no intervention related complication or neurological deficits observed in their follow-up period. Nonetheless, our study encountered some limitations, such as low patient sample and scarcity of similar experience with IORT in spine metastasis. Based on the results of this study, there is a potential in improvement of the quality of life of these patients and increased local control rate, by conduction of similar study fields with more patient sample and different application of radiation techniques to reach optimal radiation dosage and duration.

\section{Conclusion}

In current study, authors performed the first experience of application of IORT during Kyphoplasty in patients suffered from metastasis to spinal column to decline pain and improve their quality of life and local tumor control, with purpose of increment of overall survival. Our results exhibited some promising reports in pain control, quality of life and overall survival improvement. This trial, which can be considered as one of the pioneers in continuing the evaluation of efficacy of Kypho-IORT as a novel technique in these group of patients.

\section{References}

1. Coleman RE. Metastatic bone disease: clinical features, pathophysiology and treatment strategies. Cancer treatment reviews. 2001; 27: 165-176.

2. Bartels $R H$, van der Linden $Y M$, van der Graaf WT. Spinal extradural metastasis: review of current treatment options. CA: a cancer journal for clinicians. 2008; 58: 245-259.

3. Steenland E, Leer J, van Houwelingen H, Post WJ, van den Hout WB, Kievit $\mathrm{J}$, et al. The effect of a single fraction compared to multiple fractions on painful bone metastases: a global analysis of the Dutch Bone Metastasis Study. Radiotherapy and Oncology. 1999; 52: 101-109.

4. De Felice F, Piccioli A, Musio D, Tombolini V. The role of radiation therapy in bone metastases management. Oncotarget. 2017; 8: 25691: 25699.

5. Mori Y, Hashizume C, Shibamoto Y, Kobayashi T, Nakazawa H, Hagiwara M, et al. Stereotactic radiotherapy for spinal intradural metastases developing within or adjacent to the previous irradiation field-report of three case. Nagoya journal of medical science. 2013; 75: 263-271.

6. Gerszten PC, Mendel E, Yamada Y. Radiotherapy and radiosurgery for metastatic spine disease: what are the options, indications, and outcomes? Spine. 2009; 34: S78-S92.

7. Sahgal A, Bilsky M, Chang EL, Ma L, Yamada Y, Rhines LD, et al. Stereotactic body radiotherapy for spinal metastases: current status, with a focus on its application in the postoperative patient: a review. Journal of Neurosurgery: Spine 2011; 14: 151-166.

8. Tseng CL, Eppinga W, Charest-Morin R, Soliman H, Myrehaug S, Maralani $\mathrm{PJ}$, et al. Spine stereotactic body radiotherapy: indications, outcomes, and points of caution. Global spine journal. 2017; 7: 179-197.

9. Coelho TM, Fogaroli RC, Pellizzon AC, De Castro DG, Gondim GR, Silva ML. Intraoperative radiation therapy for the treatment of recurrent retroperitoneal and pelvic tumors: a single-institution analysis. Radiation Oncology. 2018; 13: 224.

10. Niewald M, Fleckenstein J, Licht N, Bleuzen C, Ruebe C. Intraoperative radiotherapy (IORT) combined with external beam radiotherapy (EBRT) for soft-tissue sarcomas-a retrospective evaluation of the Homburg experience in the years 1995-2007. Radiation Oncology. 2009; 4: 32.

11. Tokuhashi $\mathrm{Y}$, Uei $\mathrm{H}$, Oshima M. Classification and scoring systems for metastatic spine tumors: a literature review. Spine Surgery and Related Research. 2017; 1: 44-55.

12. Yahanda AT, Buchowski JM, Wegner AM. Treatment, complications, and outcomes of metastatic disease of the spine: from Patchell to PROMIS. Annals of Translational Medicine. 2019; 7: 216

13. Baskar R, Lee KA, Yeo R, Yeoh KW. Cancer and radiation therapy: current advances and future directions. International Journal of Medical Sciences. 2012; 9: 193-199.

14. Lutz ST, Jones J, Chow E. Role of radiation therapy in palliative care of the patient with cancer. Journal of Clinical Oncology. 2014; 32: 2913-2919.

15. Thomas J, Fermé C, Noordijk EM, Morschhauser F, Girinsky T, Gaillard I, et al. Comparison of $36 \mathrm{~Gy}, 20 \mathrm{~Gy}$, or no radiation therapy after 6 cycles of EBVP chemotherapy and complete remission in early-stage Hodgkin lymphoma without risk factors: Results of the EORT-GELA H9-F intergroup randomized trial. International Journal of Radiation Oncology Biology Physics. 2018; 100 : 1133-1145

16. Barnett GC, West CM, Dunning AM, Elliott RM, Coles CE, Pharoah PD, et al. Normal tissue reactions to radiotherapy: towards tailoring treatment dose by genotype. Nature Reviews Cancer. 2009; 9:134-142.

17. Eisenbrey JR, Shraim R, Liu JB, Li J, Stanczak M, Oeffinger B, et al. Sensitization of hypoxic tumors to radiation therapy using ultrasoundsensitive oxygen microbubbles. International Journal of Radiation Oncology Biology Physics. 2018; 1101: 88-96.

18. Yeo SG. Palliative radiotherapy for thoracic spine metastases: Dosimetric advantage of three dimensional conformal plans. Oncology letters. 2015; 10: 497-501.

19. Cho B. Intensity-modulated radiation therapy: a review with a physics perspective. Radiation Oncology Journal. 2018; 36: 1-10.

20. Avkshtol V, Dong Y, Hayes SB, Hallman MA, Price RA, Sobczak ML, et al. A comparison of robotic arm versus gantry linear accelerator stereotactic body radiation therapy for prostate cancer. Research and Reports in Urology. 2016; 8: 145-158.

21. Hartsell WF, Desilvio M, Bruner DW, Scarantino C, Ivker R, Roach III M, et al. Can physicians accurately predict survival time in patients with metastatic 
cancer? Analysis of RTOG 97-14. Journal of Palliative Medicine. 2008; 11 : 723-728

22. Pilar A, Gupta M, Laskar SG, Laskar S. Intraoperative radiotherapy: review of techniques and results. Ecancermedicalscience. 2017; 11: 750.

23. Kyrgias G, Hajiioannou J, Tolia M, Kouloulias V, Lachanas V, Skoulakis C et al. Intraoperative Radiation Therapy (IORT) in head and neck cancer: A systematic review. Medicine. 2016; 95: e5035.

24. Roeder F, Krempien R. Intraoperative radiation therapy (IORT) in soft-tissue sarcoma. Radiation Oncology. 2017; 12: 20.

25. Sedlmayer F, Reitsamer R, Wenz F, Sperk E, Fussl C, Kaiser J, et al. Intraoperative radiotherapy (IORT) as boost in breast cancer. Radiation Oncology. 2017; 12: 23.

26. Blandino G, Guenzi M, Belgioia L, Bonzano E, Configliacco E, Tornari E, et al. Adjuvant intraoperative radiotherapy for selected breast cancers in previously irradiated women: evidence for excellent feasibility and favorable outcomes. Reports of Practical Oncology \& Radiotherapy. 2017; 22: 277-283.
27. Krempien R, Roeder F. Intraoperative Radiation Therapy (IORT) in pancreatic cancer. Radiation Oncology. 2017; 12: 8

28. Harrison LB, Minsky BD, Enker WE, Mychalczak B, Guillem J, Paty PB, et al. High dose rate intraoperative radiation therapy (HDR-IORT) as part of the management strategy for locally advanced primary and recurrent rectal cancer. International Journal of Radiation Oncology Biology Physics. 1998; 42: $325-330$.

29. Akan A, Şimsek Ş. Intraoperative Period and Breast Cancer. The journal of breast health. 2014; 10: 190-196.

30. Sethi A, Emami B, Small Jr W, Thomas TO. Intraoperative radiotherapy with INTRABEAM: technical and dosimetric considerations. Frontiers in Oncology. 2018; 8: 74.

31. Schwid M, Donnelly ED, Zhang $\mathrm{H}$. Therapeutic analysis of Intrabeam-based intraoperative radiation therapy in the treatment of unicentric breast cancer lesions utilizing a spherical target volume model. Journal of Applied Clinical Medical Physics. 2017; 18: 184-194. 